\title{
Computer Logopedic Programm "Home Speech Therapist" For Analysis Of Speech In Correction Of Audio And Verbal Disorders In Preschool Children
}

\author{
${ }^{1}$ Nematov Sherzod, ${ }^{2}$ Kamolova Yulduzkhon \\ ${ }^{1}$ Tashkent State Technical University, Tashkent, Uzbekistan. \\ E-mail: shnematov@hotmail.com \\ ${ }^{2}$ Tashkent State Technical University, Tashkent, Uzbekistan. \\ E-mail: yulduzkhonk5155@gmail.com
}

Article History: Received:11 January 2021; Accepted: 27 February 2021; Published online: 5 April 2021

\begin{abstract}
The article provides a review of the computer program "Uy logopedi" - "Home speech therapist", used in the speech therapist to correct speech in preschool children with the Uzbek language of instruction. The characteristic features of the application of programs to the solution of speech therapy tasks are revealed.

Key words: hearing and speech impairment, software, computer programs, logo programs, children speech therapists, speech impairment, speech therapy, software restoration of hearing, voice analysis, home speech therapist.
\end{abstract}

\section{Introduction}

Nowadays computer technologies are actively used in the educational process. Many simple and complex computer programs are being created for various fields of knowledge. Depending on the age of the child and the programs used, the computer can act as an opponent in the game, be a storyteller, tutor, or examiner. There are computer programs aimed at the development of various mental functions of children: such as visual and auditory perception, attention, memory, verbal and logical thinking and others, which can be successfully used in teaching preschool children. A special place among computer programs is occupied by specialized computer programs for children with various speech disorders [1].

\section{The Importance Of Using Computer Programs In Speech Therapy}

The 21 st century is the century of modern technology where even a small child of three years old is an experienced user of computer programs. From this follows the urgent need to rebuild the already existing education system, including special education. A variety of information technologies come to the rescue, such as online services, specially designed computer logo programs. However, their presence does not mean their introduction into the educational process, since public awareness of them is not enough, the consequence of which is the present article, which provides a brief overview of the speech therapy program "Home speech therapist", which teachers use to correct and prevent human speech function. Information technologies are among the effective teaching aids, which are increasingly used in special pedagogy. One of the urgent problems of correctional pedagogy is the improvement of methods and techniques aimed at overcoming and preventing speech disorders. Timely correction of speech disorders is a prerequisite for children's psychological readiness for schooling, their adaptation to new social conditions [3].

Computer programs used for speech therapy classes must meet the following requirements.

Firstly, the program should be aimed at solving a specific speech therapy problem or disease.

Secondly, the program should be accompanied by a description of technical, methodological and pedagogical characteristics, such as: an indication of the child's age, user manual, installation requirements, etc.

Thirdly, the program should exactly match the declared characteristics: it should be bright, colorful, with sound design; the objects displayed on the screen should be large enough, understandable to the child; language should be Uzbek.

Fourth, the program should develop the child by solving specific speech and pedagogical problems, and for this, the episodes should be no longer than 3-5 minutes; the text of the task, if available, should be voiced by the announcer (with the ability to turn the sound on and off); tasks must necessarily be interesting, simple and understandable to perform, formulated at a level accessible to the child.

Analysis of computer programs in the field of speech therapy shows that the classification can be carried out for various reasons. So, they stand out: - programs aimed at the development of various mental functions: visual and auditory perception, attention and memory, verbal and logical thinking; - programs aimed at solving complex problems; - programs aimed at teaching different groups of children: children with disabilities, with a complex structure of the defect, with small speech defects; - programs that can be used by both professionals and parents; - Programs designed to educate students of future speech therapists [2].

Research and recovery of hearing in children is much more complicated than in adults and has its own specifics. 
The definition of hearing thresholds using computer audiometry on auditory caused potentials requires expensive equipment, and tonal threshold audiometry is not always obtained due to the child's misunderstanding of the proposed instructions or reluctance to perform them.

When working with children of preschool age, it is necessary to give the procedure as a gaming character to extend interest from the child [4].

Currently, the diagnosis and restoration of the auditory function in children use computer programs developed with such a calculation to make a medical event exciting $[5,6]$.

Such software for early detection of disorder and early recovery of hearing in children from 2 to 7 years old can use otolaryngologists in polyclinic or stationary conditions, as well as Pediatricians, because it successfully combines.

Corrections of defects of sound suspension occurs, as a rule, in 4 stages. Each stage has its own goal, tasks and direction of work:

Preparatory. The purpose of this stage is to prepare for the layout and its automation. For this, it is necessary to develop auditory perception in the child and attention. This manages to achieve due to the development of auditory attention, perception of speech, forming interest in leading conversation. At this stage, it is important to teach the child to breathe correctly, to develop a voice from him. Evalnamed exercises for lips, language, as well as the whole person. A special place belongs to the shallow motor.

Sound statement. The second stage is aimed at learning correctly pronounce sound in an isolated sound. For this, articulation exercises are performed on the development of the necessary muscles.

His automation. The third stage consists of developing automatically pronounced sound correctly. It is introduced into the syllable, words, etc.

Differentiation. In the last stage, the child learns to differentiate sounds on rumor - auditory perception; Fastens the ability to pronounce it correctly [7].

Analysis of the results of diagnosis of children with speech violations shows a different level of formation of phonderatic perception: from the full inability to task until some minor difficulties when performing more complex tasks. In this case, these difficulties are not always correlated with a disturbed pronunciation.

If the child does not pronounce the sounds of sounds (whistling, hissing, sonorous), then it does not differentiate. This is $47 \%$ of the total number of children surveyed with speech impairment. If a child is hampered in the pronunciation of 3-5 groups of sounds, then the phonderatic perception is broken more roughly: the child does not distinguish between almost all the sounds of the native language. This group is $35 \%$ of the number of children examined.

But there is a category of children whose sound pronunciation is not violated or is in the stage of automation of the set of the sounds, but the level of phonamematic perception is low (children are difficult in analyzing many sounds, mostly consonants). In most cases, these are the students of the first grades of secondary schools, studying on the logopunk and early visited the lessons of the speech therapist. The number of such children is $18 \%$.

The non-formation of phonderatic perception reduces the readiness to master the phonam analysis and synthesis. Often, instead of highlighting the first vowel or consonant sound, children call a syllable or all word.

The listed difficulties do not allow children to fully absorb the program of the secondary school, and in the process of learning the letter and reading they have specific errors, such as replacing consonant letters, skip, permutations, letters and syllables, replacements [8].

\section{Creation Of A Computer Program}

The basis of the hearing restoration software developed by us in Uzbek, modern computer techniques, taking into account the specifics of preschool and younger school age, are laid [9].

To create an interface, an Adobe Photoshop CS6 is used, which allows you to combine bright color gamut and control elements that contribute to a benevolent atmosphere in which the child is located during class. The design of the software is made in the animation style that uses colorful pictures, selected according to the age category and preferences of preschool age.

The program starts in the window mode.

After starting, the main program window appears in Fig.1.

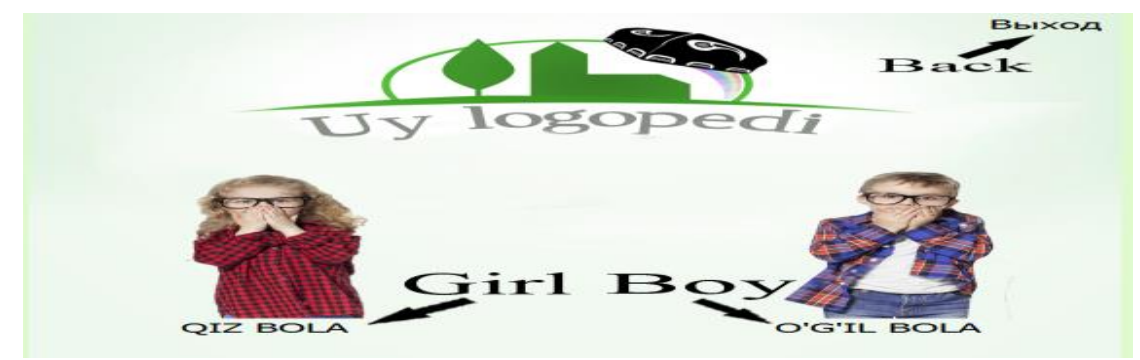

Fig. 1. Main window. 
The main menu is the two main functional Prices: Qiz bola and O'g'il Bola, used to start working with the program and to exit the program, respectively. After clicking on the "Qiz bola" and "O'g'il bola" button, there is a transition in the selection menu of the program partitions. The program includes 7 major sections corresponding to a specific subject (Fig. 1).

Access to each of the partitions is carried out through the main menu.

On this form there are basic elements of navigation - the names of the sections, when activating which the transition to them is activated: Seasons - «Fasllar»; Animals - «Hayvonlar; Wild animals- «Yovvoyi hayvonlar»; Fruits- «Mevalar»; Object name - «Predmet nomlari va boshqalar»; Relatives - «Qarindoshlar»; Numbers «Raqamlar»; Vegetables - «Sabzavotlar»; Natural phenomena - «Tabiat hodisalari».

Each click of the mouse button on the image in the thematic section has voice support - a girl and a speaker boy in Uzbek language pronounces the name of the subject. The child's task under the supervision of a specialist or one of the parents includes multiple listening of the word denoting the drawn object, comparing it with the visual image and the pronouncing heard. In order for the children to be more interesting and not boring to do, the child can listen to the newly uttered record. When working with the program, taking into account the degree of hearing loss, you can set the individual degree of volume gains with the help of equalizers implemented on the basis of modern sound cards, as well as the available sound-drying equipment

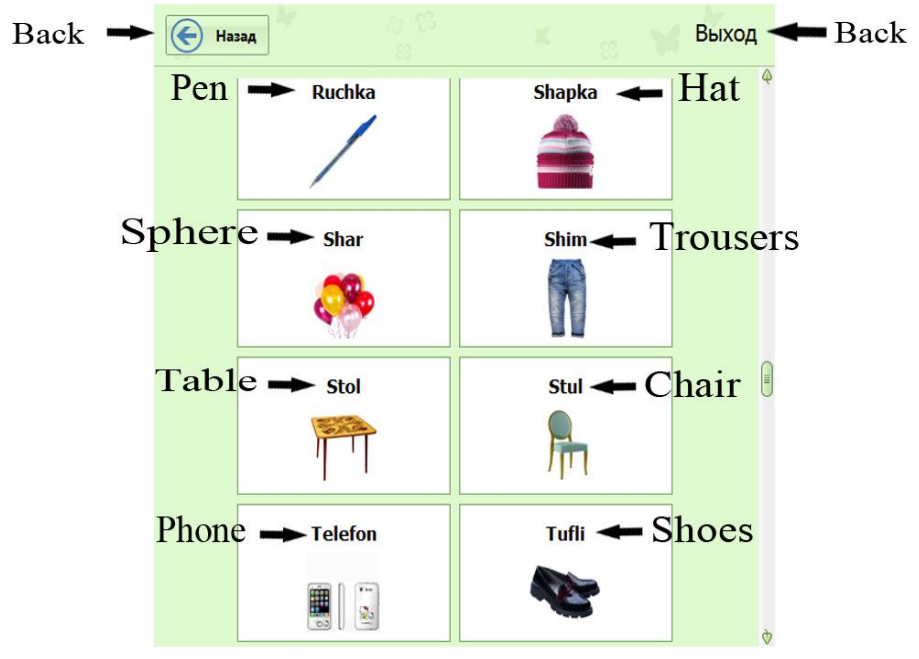

Fig. 2. Name of items.

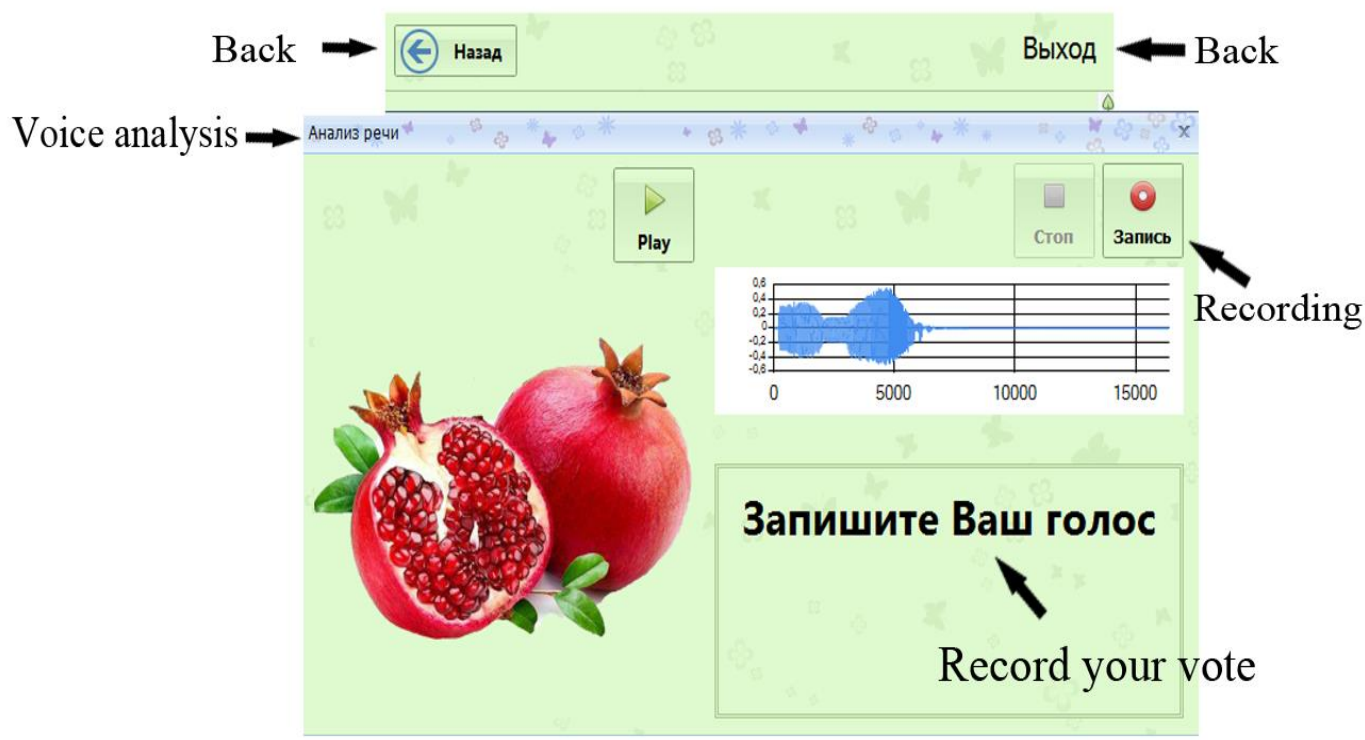

Fig. 3. With the press "Play" sound is played. 


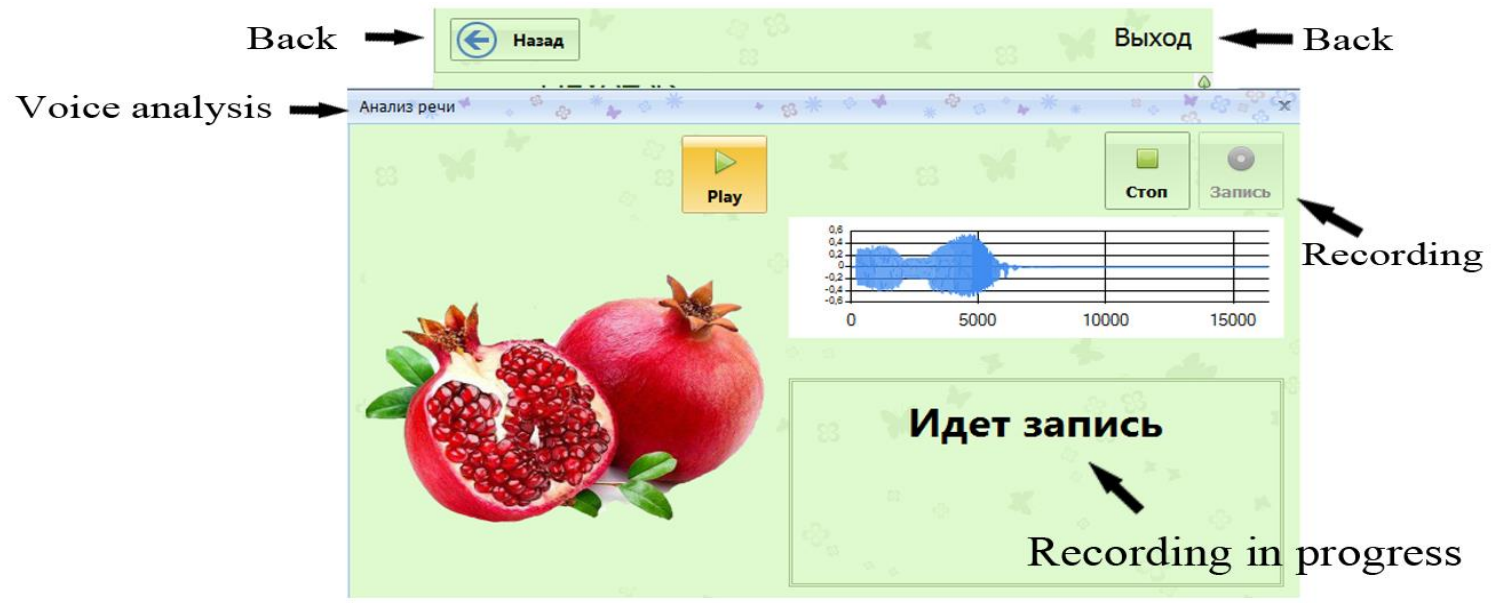

Fig. 4. The process of voice recording.

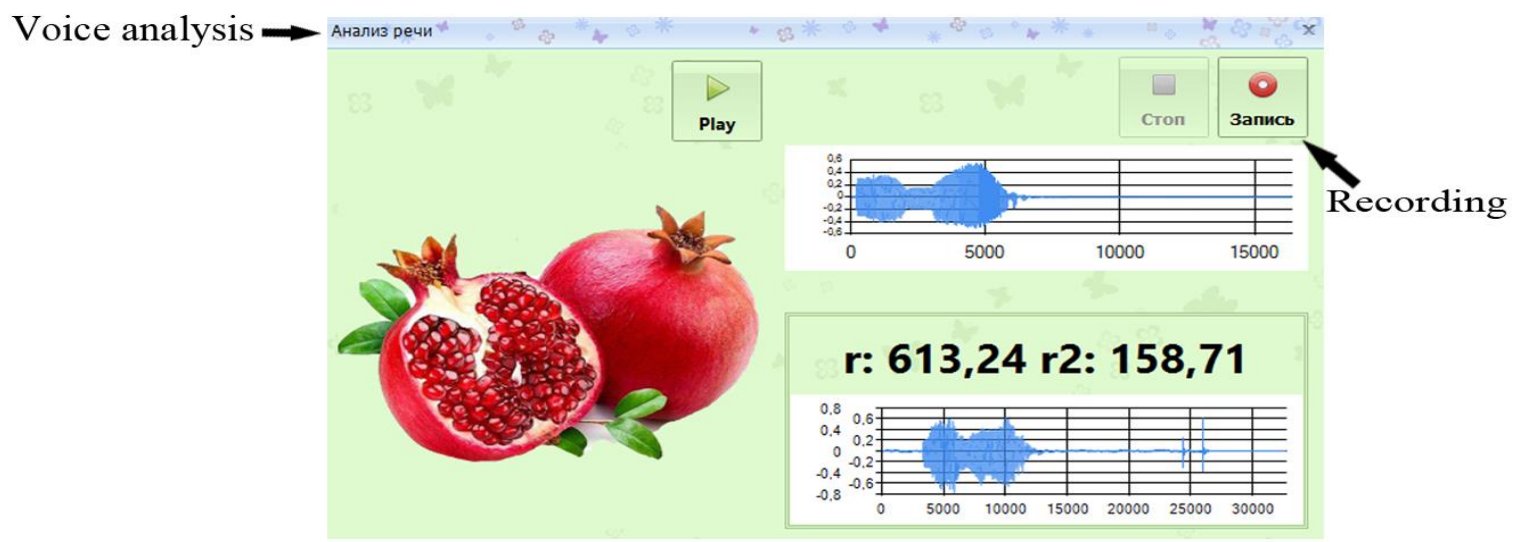

Fig. 5.. The process of comparing and analyzing the voice.

sample_path =_sample_path;

Program Code

InitializeComponent(); progress_p1. Visible = false;

mic_data = new byte[0];

btn_start.Enabled = true;

btn_stop.Enabled = false;

chart_mic. Visible $=$ false;

label_result.Text = "OVOZNI YOZING";

is_boy $=$ _is_boy;

label_name.Text =_w_name;

\section{Conclusion}

The program developed by us in the Uzbek language is convenient for use in the process of teaching and speech correction for speech therapists, as well as interesting for preschool children. The computer's auditory program developed by us is introduced into the medical and diagnostic process of the phoniatric branch of the clinics, as well as in the educational process of the Department "Otorinolaryngology" of the Tashkent Medical Academy and Biomedical Engineering of the Tashkent state Technical University named after Islam Karimov.

\section{References}

1. https://tabanova-maegords6.edumsko.ru/articles/post/806720

2. M. A. Kislyakova, A. Bytsay, E. Boshtovenko A review of computer programs for a speech therapist Electronic scientific publication "Scientific notes of PNU" (Khabarovsk) 2016, Volume 7, No. 4, P. $499-503$ 
3. Kitik, E.E. The use of information technology in the process of training speech therapists: a training computer program "Articulating sound patterns are normal" [Text] / E.E. Kitik // Defectology. - 2007. No. 3. - S. 73-83.

4. http://www.phys.unsw.edu/ jw/hearing

5. Vasilyeva S.A., Gaibnazarov B.B., Kimizbaeva A.E. The method of product implementation of testing and correction of hearing in children // Journal of TSTU, 2013, №2.-C.46-48.

6. Akbarkhodzhayev Sh. N., Vasilyeva S.A. Use computer technologies in listen and speach. Reports of the Republican Scientific and Technical Conference "Problems of Information and Telecommunication Technologies" Part 2, Tashkent: TUIT, 10-18 march, 2016.,c. 322-325.

7. https://psyh.info/article/otkloneniya-v-razvitii-rebenka/narushenie-rechi-u-detej.html

8. https://nsportal.ru/shkola/korrektsionnaya-pedagogika/library/2014/12/13/diagnostikafonematicheskogo-vospriyatiya

9. Kamolova Yu.M. Computer software "Home Speech Therapist" for speech analysis in the correction of auditory and speech disorders in preschool children. Polish Journal of Science. Poland. 2019 -39-47p. 